Published in final edited form as:

Clin Gastroenterol Hepatol. 2015 April ; 13(4): 799-804. doi:10.1016/j.cgh.2014.07.056.

\title{
Suboptimal Knowledge of and Surveillance for Hepatocellular Carcinoma by Primary Care Providers
}

\author{
Christopher E. McGowan, MD, MSCR${ }^{1}$, Teresa P. Edwards, BS, MA², Mai-Uyen T. Luong, \\ $\mathrm{BA}^{1}$, and Paul H. Hayashi, MD, MPH ${ }^{1}$ \\ ${ }^{1}$ UNC Liver Center Division of Gastroenterology and Hepatology Burnett-Womack Bldg., Room \\ 8011 Chapel Hill, NC 27599-7584
}

${ }^{2} \mathrm{H}$. W. Odum Institute for Research in Social Science University of North Carolina - Chapel Hill CB\# 3355, 231D Davis Library Chapel Hill, NC 27599-3355

\section{Abstract}

Background \& Aims-A large proportion of patients with cirrhosis are seen only by their primary care provider (PCP). Surveillance for hepatocellular carcinoma (HCC) therefore depends on PCPs in these cases. We aimed to assess PCP knowledge and practice of HCC surveillance.

Methods-We contacted a random sample of 1000 North Carolina PCPs by mail. All received an introductory letter, followed by a 12-item questionnaire addressing HCC surveillance knowledge and practice.

\begin{abstract}
Results-Three hundred ninety-one PCPs (39\%) completed the survey; 89\% saw patients with cirrhosis in their practice, but only 45\% screened for HCC. Among PCPs who screened, the most common methods were ultrasound analysis and measurement of $[a]$ fetoprotein $(66 \%)$. Reasons for surveillance included supported by evidence (72\%), recommended by medical societies (42\%), and malpractice liability for not surveilling (26\%). Of PCPs who did not screen, $84 \%$ referred to gastroenterologists for surveillance decisions, $24 \%$ were unaware of recommendations, $8 \%$ were uncertain of the benefits, and $8 \%$ were concerned over cost. Hepatic resection and liver transplantation were identified as effective therapies by $67 \%$ and $56 \%$ of PCPs, but all other effective therapies were identified by less than half (transarterial chemoembolization by $42 \%$,
\end{abstract}

(C) 2014 Published by The AGA Institute

Corresponding author: Paul H. Hayashi, MD, MPH Burnett-Womack Bldg., Room 8011 Chapel Hill, NC 27599 P: 919-966-2516 F: 919-966-1700 paul_hayashi@med.unc.edu.

Publisher's Disclaimer: This is a PDF file of an unedited manuscript that has been accepted for publication. As a service to our customers we are providing this early version of the manuscript. The manuscript will undergo copyediting, typesetting, and review of the resulting proof before it is published in its final citable form. Please note that during the production process errors may be discovered which could affect the content, and all legal disclaimers that apply to the journal pertain.

CEM: study concept and design; acquisition of data; analysis and interpretation of data; drafting of the manuscript; critical revision of the manuscript for important intellectual content; statistical analysis; obtained funding; administrative, technical support.

TPA: study design; analysis and interpretation of data.

MTL: acquisition of data

PHH: study concept and design; acquisition of data; analysis and interpretation of data; drafting of the manuscript; critical revision of the manuscript for important intellectual content; statistical analysis; obtained funding; administrative, technical, or material support; study supervision.

Conflict of Interest: None of the authors have any conflict of interests to disclose.

Writing assistance: none 
radiofrequency ablation by $35 \%$, sorafenib by $26 \%$ ). Ability to identify at least 1 effective therapy was independently associated with surveillance (odds ratio, 2.1; 95\% confidence interval, 1.1-4.0)

Conclusions-Most PCPs see patients with cirrhosis, but only a minority screen for HCC. PCP knowledge of effective HCC therapy options is suboptimal. Efforts to enlist PCPs in HCC surveillance may be best served by increasing their knowledge of effective therapies.

\section{Keywords}

therapy; screening; hepatitis C; hepatitis B; cirrhosis

\section{INTRODUCTION}

Hepatocellular carcinoma surveillance is recommended by all three major hepatology societies.(1-3) Nevertheless, surveillance rates remain well below 50\% and in some populations as low as 12\%.(4-7) Among the many steps needed for surveillance to be accomplished, physician education and incorporation of surveillance into their practice are critical. As expected, hepatologists and gastroenterologists tend to believe in surveillance and are more likely to routinely order it for their cirrhotic patients $(5,7)$ but only $20-50 \%$ of such patients are seen by such subspecialists. $(7,8)$ Primary care providers (PCPs) see most of the remainder.

Therefore, if surveillance is to have any chance of reaching more than $50 \%$ of cirrhosis patients, enlistment of PCPs will be necessary. Only 3 studies have investigated the practice and knowledge of HCC surveillance amongst PCPs and these 3 focused primarily on PCPs who see a high number of Asian patients or on surveillance for viral hepatitis rather than HCC surveillance. (9-11) Therefore we sampled PCPs from the entire North Carolina Medical Board database and limited our questionnaire to HCC surveillance only.

\section{METHODS}

\section{Institutional Review of Research}

Our research project and protocol were reviewed and approved by the University of North Carolina Institutional Review Board prior to initiating this study.

\section{Subjects}

We used the North Carolina Medical Board database to identify practicing primary care providers (physicians and doctors of osteopathy) in North Carolina. A random sample of 1000 PCPs was identified. This sample represented 14\% of North Carolina PCP's (12),(13)

\section{Survey}

Survey methodology is based on the tailored design method.(14) All subjects received an introductory letter, followed by the questionnaire in a separate mailing. The questionnaire consisted of 8-items addressing knowledge and use of HCC surveillance guidelines as well as identification of HCC therapies. Basic demographics and practice information requested was limited to gender, years in practice, major affiliations (e.g. academic facility, Veterans 
Affairs, private practice) and their ability to see Medicaid covered patients. We purposely did not request more specific information that would lengthen the questionnaire, compromise anonymity and potentially lower the response rate. Therefore we did not collect information on practice location, type of service area (rural versus urban), training, or specific type of practice (i.e. group versus solo, family practice versus internal medicine) or personal perceptions of surveillance efficacy. Such limiting of variables did not allow us to construct a conceptual behavioral model for the decision to recommend surveillance. Instead, we focused on self-reported rate of surveillance, and the modality and interval recommended. We also asked about knowledge of $\mathrm{HCC}$ therapies because they have changed substantially in the last decade and remain a primary justification for surveillance. No pre-testing or validation of this brief survey were done. A \$10 cash incentive was included to reduce non-response bias and was given regardless of whether the PCP completed the questionnaire or not. A reminder/gratitude postcard was mailed to all subjects, followed by the mailing of a second questionnaire for non-responders. Addressed return envelope with pre-paid postage was included.

To ensure anonymity, all questionnaires were given an alphanumeric code. The master key linking code to subject name was used only at the mail out and receipt portion of the study to determine who should receive a second chance mailing. Data collection (receipt of questionnaires) was closed 90 days after the last mailing was completed. Thereafter the master key was destroyed and no further questionnaires were collected or mailed out.

\section{Analysis}

Demographic, practice information, and survey responses were analyzed using basic descriptive statistics (e.g. means, medians, proportions, standard deviations). We used Pearson Chi-Square and T-test where appropriate to compare PCPs who screened and those that did not. Logistic regression was used to identify independent variables associated with surveillance.

\section{RESULTS}

\section{Subjects (PCPs)}

Of the 1000 PCPs to whom we mailed letters and questionnaires, 391 (39\%) completed the questionnaire and mailed it back to us. Two PCPs answered questions in an incongruent or unclear manner and had to be discarded (one PCP indicated not seeing cirrhotic patients yet did surveillance; another did not answer whether they saw cirrhotic patients, but indicated they do not screen.) Characteristics of the remaining 389 PCPs is shown in Table 1 . The vast majority was in private practice and saw Medicaid patients. Nearly $90 \%$ saw cirrhotic patients in their practices.

\section{Hepatocellular carcinoma (HCC) surveillance}

Of the 345 PCPs that saw cirrhotic patients, only $45 \%$ recommended HCC surveillance. There were no significant differences between those PCPs who do recommend surveillance $(n=156)$ from those who don't $(n=189)$ in terms of gender, years in practice, practice affiliation and whether they see Medicaid patients. The most common means of surveillance 
used was liver ultrasound and alpha-fetoprotein measurement. (Figure 1) The most common interval for surveillance was 12 months. (Figure 2) Nearly three quarters of those who provide surveillance do so because they felt evidence supported it (Table 2). When asked to identify barriers to surveillance, 54\% identified poor patient adherence and 53\% identified patient financial constraints, $49 \%$ lack of insurance and $32 \%$ insurance constraints on coverage. Only 5\% identified lack of available surveillance services (e.g. radiology) as a barrier.

Among those who do not recommend surveillance, the vast majority ( $84 \%)$ defer to subspecialists to decide or carry out surveillance (Table 3). However, 46 (24\%) were unaware of any surveillance recommendations, while only $15(8 \%)$ felt the benefit of surveillance was uncertain. Only $4 \%$ identified cost as a reason for not recommending surveillance.

\section{Knowledge of HCC therapies and association with surveillance}

Of the 345 PCPs who see cirrhosis patients, $230(67 \%)$ identified resection as an effective therapy for HCC, but only 192 (56\%) identified liver transplant. (Table 4) Other effective treatments were identified less frequently. PCPs who were able to identify at least one modality as an effective therapy were more likely to screen with an odds ratio of $1.9(\mathrm{p}=$ 0.04). On multivariate analysis (controlling for PCP gender, practice setting, years in practice and whether they see Medicaid patients), the association between identifying at least one effective therapy and recommending surveillance remained significant (OR 2.1, $95 \%$ confidence interval $1.1-4.0$ ). None of the other variables were significantly associated with recommending surveillance.

\section{DISCUSSION}

While formally recommended by hepatology societies for nearly a decade, less than half (25-42\%) of cirrhotic patients receive HCC surveillance according to several studies.(4-7) Such low rates may be because $20-50 \%$ of cirrhosis patients are not seen by gastroenterologists who tend to recommend surveillance more than PCPs.(7, 8) Even after being seen by a gastroenterologist, patients may see their PCP more frequently, especially in remote regions where the distance to a subspecialist is greater. If surveillance is to ever have a sustainable rate over 50\%, enlistment of PCP help will probably be necessary. However, data regarding PCP knowledge and beliefs regarding HCC surveillance are limited.

Our study indicates that only $45 \%$ of primary care providers who see cirrhosis patients in North Carolina recommend surveillance. About $70 \%$ of PCPs who screen, do so because they feel evidence supports it. Forty-two percent understood that some medical associations recommend it. Of the majority that do not screen, $84 \%$ deferred to subspecialists to recommend or consider surveillance, and $24 \%$ were unaware of surveillance recommendations. Only resection and transplantation were correctly identified as effective therapies by more than half of all respondents (67\% and 56\% respectively). (Table 4) Only $35 \%$ identified RFA, even though data suggest it rivals resection in efficacy and is significantly less morbid. (15-17). Similarly, only a minority of PCPs identified TACE and sorafenib despite randomized controlled trials (RCT) showing survival benefit. $(18,19)$ 
Those PCP's able to identify at least one effective treatment were twice as likely to recommend surveillance.

Of those who do surveillance, US and AFP, in combination, was most commonly used, and 12 months the most common interval. (Figures $1 \& 2$ ). These data may reflect older AASLD recommendations of 2005 in which AFP was mentioned as an alternative option, if US is suboptimal or unavailable, and the suggested interval was up to 12 months. In 2010, the AFP was completely dropped and the interval limited to 6 months.

Two studies reported higher rates of surveillance among PCPs (79-89\%), but the PCPs in these studies were highly biased toward increased HCC awareness. Both studies targeted PCPs from communities with high proportions of Asians who have significantly higher prevalences of hepatitis B infection and consequent cirrhosis. Also, PCPs in these studies may recommend surveillance more often because supporting evidence is stronger (Level I, RCT data) for surveillance in hepatitis B related liver disease (20) than cirrhosis from other etiologies (Level II, observational, cohort data) (21). One study surveyed 11 San Francisco clinics with a patient population that is $25 \%$ Asian.(10) Moreover, 1 in 4 of the PCPs themselves were Asian and half had patient panels that were $>25 \%$ Asian. The other study surveyed 3 Northern California counties, but again 1 in 4 of the PCPs were Asians, $43 \%$ spoke an Asian language and 30\% of their catchment was Asian.(9) Such PCP groups will have an increased interest in HCC surveillance compared to PCPs from other areas of the U.S. The nation as a whole is only $5 \%$ Asian.(22) The only other study examining PCPs focused primarily on surveillance for hepatitis C and B infections.(11) HCC surveillance questions were limited and did not specify the presence or absence of cirrhosis. None of the three studies asked about HCC therapies or whether respondents actually see cirrhosis patients in their practices.

We focused on HCC surveillance and therapy. We surveyed a random sample of PCPs from across the state of North Carolina. Therefore, our data are more representative of communities with Asian prevalence closer to the national average. Only $2.5 \%$ of North Carolina are of Asian descent.(13) Unlike prior surveys we also asked whether PCPs actually saw cirrhosis patients in their practice. Such determination is critical since PCPs may render an opinion on HCC surveillance but never actually see a cirrhotic patient. Some may divert cirrhosis patients away from their clinic, or work in clinics where cirrhosis patients are rare (e.g. student health clinics).

We also wanted to understand PCP knowledge of HCC therapies because effective therapies are arguably the most compelling justification for surveillance. $(1,23)$ HCC therapies have evolved greatly in the last 12 years. Our survey suggests that PCP knowledge of more recently established treatments is relatively poor compared to established surgical interventions. Filling this knowledge gap regarding RCT data for TACE, RFA and sorafenib, could increase surveillance rates by PCPs since the ability to identify at least one effective therapy was independently doubled the odds of surveillance. Also, over $80 \%$ of PCPs who do not screen deferred the decision to subspecialists, and despite some controversy in the literature regarding HCC surveillance recommendations, (23-25) only $8 \%$ 
did not screen because the "benefit is uncertain". Therefore, a large number of PCPs may recommend surveillance, if guidance and education are provided.

Our study is limited by a response rate (39\%) that is lower than prior HCC surveillance surveys of PCPs $(62-71 \%) .(9,10)$ As mentioned, these prior studies targeted Asian community PCPs who very likely have a deeper knowledge and interest in HCC. Our response rate is more in line with less targeted provider surveys. An analysis of 130 surveys of US health care professionals, conducted from 1996 to 2005 yielded a median response rate of $51 \%$ with an interquartile range of $38-65 \%$.(26) Moreover, the response rate for health care professionals declined significantly with the percent of surveys having $>60 \%$ response falling from $63 \%$ prior to 2000 to $35 \%$ in 2005-2008.(27) PCPs who see pertinence in a survey and have increased knowledge of the topic tend to respond more often, hence the higher response rates in the studies from California. $(9,10,28)$ Such a response bias in our study would make our surveillance and knowledge of therapy rates overestimates of the true rate amongst PCPs in our state. Moreover, recall bias by those who said they recommend surveillance may further overestimate the rate.

Our survey is also limited in scope. The questionnaire was purposely kept brief to limit the non-response rate. Many other variables needed for a full behavior model such as PCP access to subspecialists and volume of cirrhotic patients seen were not included. Thus, therapy knowledge that was associated with surveillance may be merely a surrogate for other more pertinent variables not captured in our survey.

Our study provides the only data on HCC surveillance and knowledge of HCC therapy in an unselected population of PCPs who see cirrhotic patients in practices not enriched with Asians. The data suggest that HCC surveillance rates and knowledge of therapies are low. It also suggests an opportunity to increase community surveillance rates by closing the gap in knowledge, particularly regarding effective therapy options. Moreover the majority of PCPs who do not screen may be amenable to surveillance if educated and guided by subspecialists. Enlisting PCP help in initiating surveillance may eliminate unnecessary referral for opinion and certainly will help with sustaining surveillance once started. It is probably the only practical way to increase and sustain surveillance rates on a broader scale.

\section{Acknowledgments}

Funding: Onyx Pharmaceuticals, an Amgen subsidiary through an unrestricted grant.

\section{Abbreviations}

$\begin{array}{ll}\text { AFP } & \text { alpha fetoprotein } \\ \text { CT } & \text { computerized tomography } \\ \text { HCC } & \text { hepatocellular carcinoma } \\ \text { MRI } & \text { magnetic resonance imaging } \\ \text { PCP } & \text { primary care provider }\end{array}$




$\begin{array}{ll}\text { RFA } & \text { radiofrequency ablation } \\ \text { TACE } & \text { transarterial chemoembolization } \\ \text { U.S. } & \text { United States of America } \\ \text { US } & \text { ultrasound }\end{array}$

\section{References}

1. Bruix J, Sherman M. Management of hepatocellular carcinoma: an update. Hepatology. 2011; 53(3): 1020-2. [PubMed: 21374666]

2. Omata M, Lesmana LA, Tateishi R, Chen PJ, Lin SM, Yoshida H, et al. Asian Pacific Association for the Study of the Liver consensus recommendations on hepatocellular carcinoma. Hepatol Int. 2010; 4(2):439-74. [PubMed: 20827404]

3. EASL-EORTC clinical practice guidelines: management of hepatocellular carcinoma. J Hepatol. 2012; 56(4):908-43. [PubMed: 22424438]

4. Davila JA, Weston A, Smalley W, El-Serag HB. Utilization of screening for hepatocellular carcinoma in the United States. J Clin Gastroenterol. 2007; 41(8):777-82. [PubMed: 17700427]

5. Davila JA, Morgan RO, Richardson PA, Du XL, McGlynn KA, El-Serag HB. Use of surveillance for hepatocellular carcinoma among patients with cirrhosis in the United States. Hepatology. 2010; 52(1):132-41. [PubMed: 20578139]

6. Davila JA, Henderson L, Kramer JR, Kanwal F, Richardson PA, Duan Z, et al. Utilization of surveillance for hepatocellular carcinoma among hepatitis $C$ virus-infected veterans in the United States. Ann Intern Med. 2011; 154(2):85-93. [PubMed: 21242365]

7. Palmer LB, Kappelman MD, Sandler RS, Hayashi PH. Surveillance for hepatocellular carcinoma in a Medicaid cirrhotic population. J Clin Gastroenterol. 2013; 47(8):713-8. [PubMed: 23442840]

8. Sanyal A, Poklepovic A, Moyneur E, Barghout V. Population-based risk factors and resource utilization for HCC: US perspective. Curr Med Res Opin. 2010; 26(9):2183-91. [PubMed: 20666689]

9. Nguyen TT, Gildengorin G, Truong A, McPhee SJ. Factors influencing physicians' screening behavior for liver cancer among high-risk patients. J Gen Intern Med. 2007; 22(4):523-6. [PubMed: 17372804]

10. Khalili M, Guy J, Yu A, Li A, Diamond-Smith N, Stewart S, et al. Hepatitis B and hepatocellular carcinoma screening among Asian Americans: survey of safety net healthcare providers. Dig Dis Sci. 2011; 56(5):1516-23. [PubMed: 21046247]

11. Ferrante JM, Winston DG, Chen PH, de la Torre AN. Family physicians' knowledge and screening of chronic hepatitis and liver cancer. Family medicine. 2008; 40(5):345-51. [PubMed: 18465284]

12. Studies AoAMCCfW. [2014 March 25] State Physician Workforce Data Book: AAMC; 2011. 2011. Available from: https://www.aamc.org/download/263512/data/statedata2011.pdf

13. Bureau, USC. State \& County QuickFacts. U.S. Department of Commerce; 2014. Available from: http://quickfacts.census.gov/qfd/states/37000.html [2014 March 25]

14. Dillman, D.; Smyth, J.; Christian, J. Internet, mail, and mixed-mode surveys: the tailored design method. John Wiley \& Sons; Hoboken, NJ: 2009.

15. Chen MS, Li JQ, Zheng Y, Guo RP, Liang HH, Zhang YQ, et al. A prospective randomized trial comparing percutaneous local ablative therapy and partial hepatectomy for small hepatocellular carcinoma. Ann Surg. 2006; 243(3):321-8. [PubMed: 16495695]

16. Huang J, Yan L, Cheng Z, Wu H, Du L, Wang J, et al. A randomized trial comparing radiofrequency ablation and surgical resection for HCC conforming to the Milan criteria. Ann Surg. 2010; 252(6):903-12. [PubMed: 21107100]

17. Feng K, Yan J, Li X, Xia F, Ma K, Wang S, et al. A randomized controlled trial of radiofrequency ablation and surgical resection in the treatment of small hepatocellular carcinoma. J Hepatol. 2012; 57(4):794-802. [PubMed: 22634125] 
18. Lo CM, Ngan H, Tso WK, Liu CL, Lam CM, Poon RT, et al. Randomized controlled trial of transarterial lipiodol chemoembolization for unresectable hepatocellular carcinoma. Hepatology. 2002; 35(5):1164-71. [PubMed: 11981766]

19. Llovet J, Ricci S, Mazzaferro V, Hilgard P, Raoul J, Zeuzem S, et al. Randomized phase III trail of sorafenib versus placebo in patients with advanced hepatocellular carcinoma. Journal of Clinical Oncology. 2007; 25(Supplement 18)(18S):LBA1.

20. Zhang BH, Yang BH, Tang ZY. Randomized controlled trial of screening for hepatocellular carcinoma. Journal of cancer research and clinical oncology. 2004; 130(7):417-22. [PubMed: 15042359]

21. Singal AG, Pillai A, Tiro J. Early detection, curative treatment, and survival rates for hepatocellular carcinoma surveillance in patients with cirrhosis: a meta-analysis. PLoS medicine. 2014; 11(4):e1001624. [PubMed: 24691105]

22. Bureau, USC. State and County QuickFacts. U.S. Department of Commerce; 2013. Available from: http://quickfacts.census.gov/qfd/states/00000.html [2014 March 25]

23. Sherman M, Bruix J, Porayko M, Tran T. Screening for hepatocellular carcinoma: the rationale for the American Association for the Study of Liver Diseases recommendations. Hepatology. 2012; 56(3):793-6. [PubMed: 22689409]

24. Lederle FA, Pocha C. Screening for liver cancer: the rush to judgment. Ann Intern Med. 2012; 156(5):387-9. [PubMed: 22393134]

25. Kansagara D, Papak J, Pasha AS, O'Neil M, Freeman M, Relevo R, et al. Screening for Hepatocellular Carcinoma in Chronic Liver Disease: A Systematic Review. Ann Intern Med. 2014

26. Cook JV, Dickinson HO, Eccles MP. Response rates in postal surveys of healthcare professionals between 1996 and 2005: an observational study. BMC Health Serv Res. 2009; 9:160. [PubMed: 19751504]

27. McLeod CC, Klabunde CN, Willis GB, Stark D. Health care provider surveys in the United States, 2000-2010: a review. Evaluation \& the health professions. 2013; 36(1):106-26. [PubMed: 23378504]

28. Klabunde CN, Willis GB, Casalino LP. Facilitators and barriers to survey participation by physicians: a call to action for researchers. Evaluation \& the health professions. 2013; 36(3):27995. [PubMed: 23975758] 


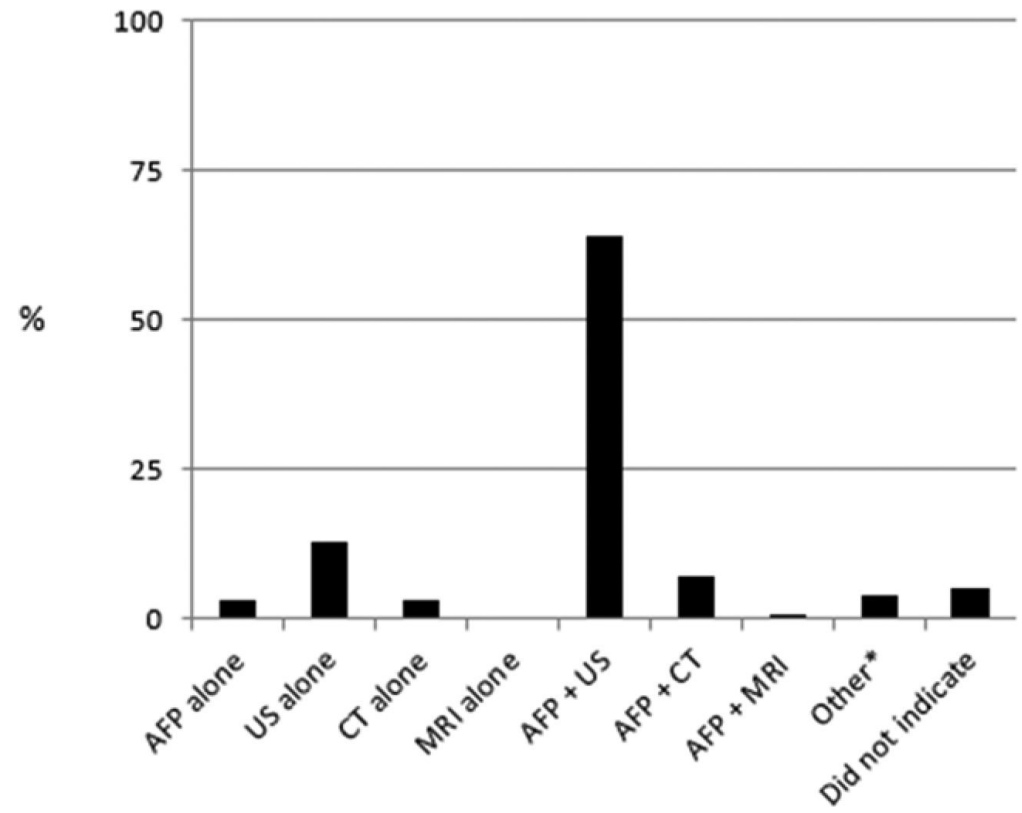

Figure 1.

Modality of HCC surveillance used by those primary care providers who screen $(\mathrm{n}=156)$ * "Other" category for modality: 2 PCPs indicated they would do what the subspecialist recommends, while 4 used AFP, US, CT and MRI in various combinations and alternating fashion (e.g. AFP + US every 6 months and CR or MRI every 2 years). 


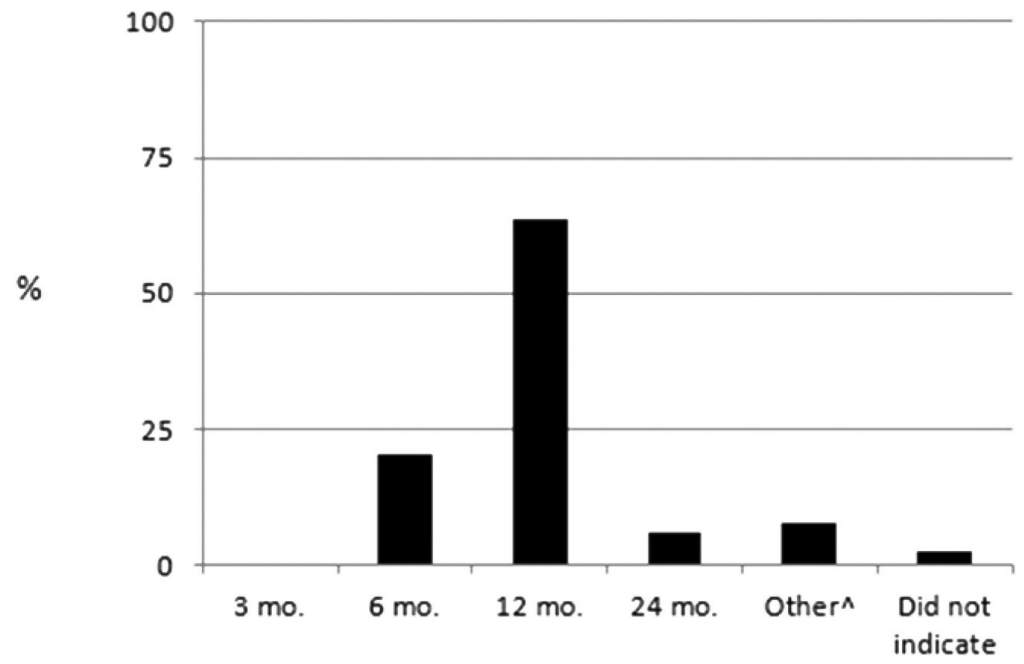

Figure 2.

Interval of HCC surveillance used by those primary care providers who screen $(n=156){ }^{\wedge}$ "Other" category for interval: 2 PCPs gave ranges of 6-12 months, 5 indicated taking cues from subspecialists and 8 gave unclear answers for interval (e.g. "depends" and "periodically" and "if liver enzymes rise"). AFP = alpha-fetoprotein, US = ultrasound, CT = computerized tomography, MRI = magnetic resonance imaging. 


\section{Table 1}

Characteristics of primary care providers $(\mathrm{n}=389)$

\begin{tabular}{|lrr|}
\hline Characteristic & & \\
\hline Male, $\mathbf{n}(\%)$ & 234 & $(60.2)$ \\
\hline Years in practice (mean, standard deviation) & 22 & $(9.9)$ \\
\hline Primary affiliation, $\mathbf{n}(\%)$ & & \\
$\quad$ Private practice & 313 & $(80.5)$ \\
$\quad$ Academic setting & 47 & $(12.1)$ \\
$\quad$ Veterans Affairs hospital or clinic & 13 & $(3.3)$ \\
$\quad$ Health maintenance organization (HMO) & 4 & $(1.0)$ \\
$\quad$ Other (not specified by respondent) & 12 & $(3.1)$ \\
\hline Encounter cirrhotic patients in practice, $\mathbf{n}(\%)$ & 345 & $(88.7)$ \\
\hline
\end{tabular}




\section{Table 2}

Reasons for recommending HCC surveillance among those PCPs that screen, $\mathrm{n}=156$ (respondents asked to choose all that apply)

\begin{tabular}{|lrc|}
\hline & $\mathbf{n}$ & $\%$ \\
\hline Evidence supports surveillance for HCC & 112 & 72 \\
\hline Surveillance is recommended by medical societies & 65 & 42 \\
\hline Not surveillance would pose a malpractice liability & 41 & 26 \\
\hline Surveillance for HCC is cost-effective & 26 & 17 \\
\hline Other $^{*}$ & 12 & 8 \\
\hline Did not give a reason & 4 & 3 \\
\hline
\end{tabular}

* Other reasons given: Affects treatment options; it is standard with our cirrhosis clinic; It's what I would do; patients request it; r/o liver lesion affecting labs etc.; recommended by consultant (gastroenterologist or hepatologist). 


\section{Table 3}

Reasons for not recommending HCC surveillance among those PCPS that do not screen, $\mathrm{n}=189$ (respondents asked to choose all that apply)

\begin{tabular}{|lrc|}
\hline & $\mathbf{n}$ & $\boldsymbol{\%}$ \\
\hline Refer cirrhotic patients to consulting provider & 158 & 84 \\
\hline Did not know it was recommended & 46 & 24 \\
\hline Benefit of surveillance is uncertain & 15 & 8 \\
\hline Too costly & 8 & 4 \\
\hline Other $^{*}$ & 8 & 4 \\
\hline Did not give a reason & 0 & 0 \\
\hline
\end{tabular}

* Other reasons given: Transient population; I screen the hepatitis C cirrhotics/not usually the alcoholic cirrhotics; Not sure of latest recommendations; See few cirrhotics + usually terminal or followed by specialists; Only check with hep C; Ultrasound often done as diagnosis of cirrhosis evolving; Usually do not live long enough; I intend to but some slip through 


\section{Table 4}

Effective HCC therapies identified by PCPs who see cirrhosis patients, $n=345$ (respondents asked to choose all that apply)

\begin{tabular}{|lrr|}
\hline & $\mathbf{n}$ & $\%$ \\
\hline Hepatic resection & 230 & 67 \\
\hline Liver transplantation & 192 & 56 \\
\hline Transarterial chemoembolization & 146 & 42 \\
\hline Radiofrequency ablation & 121 & 35 \\
\hline Sorafenib & 91 & 26 \\
\hline Did not identify any choices as effective therapies & 50 & 15 \\
\hline
\end{tabular}

